\title{
¿Enseñamos Evo-Devo?: Implicaciones de las nuevas hipótesis sobre evolución biológica y su incidencia en la escuela.
}

\section{Do we teach Evo-Devo?: Implications of new hypotheses about biological evolution and its implications on the school.}

Por: Germán Alberto Cháves Mejía. ${ }^{1}$

Recibido: 01-04-2010

Aceptado: 05-06-2010

La evolución se ve intensamente condicionada por la naturaleza conservadora de los programas embriológicos. Nada en la biología es tan complejo como producir un adulto... a partir de un simple huevo fertilizado. Nada se puede cambiar radicalmente sin descoyuntar el embrión. (Stephen Jay Gould, 1977. Ontogeny and Phylogeny p. 202)

\section{Resumen}

Si bien la enseñanza de la teoría evolutiva hace parte de los estándares curriculares dados por el Ministerio de Educación Nacional (MEN), los avances que han acaecido en las últimas tres décadas acerca de los mecanismos evolutivos no existen explícitamente como un estándar a enseñar en el área de Biología en las escuelas. Lo anterior podría ser debido a falta de una continua actualización de los programas de biología, lo cual debería ser imperante, ya que así como avanzan explicaciones de nuevos mecanismos, ritmo y factores de la evolución biológica, así mismo estos avances deberían y deben ser enseñados en la escuela. Teniendo en cuenta esto, este ensayo tratará de dar una visión general sobre cómo surgió la hipótesis Evo-Devo (evolutionary and development biology) y cómo posiblemente debería ser entendida y enseñada por los maestros de ciencias biológicas en pos de mejorar y actualizar los procesos de enseñanza y aprendizaje de la biología en las aulas.

Palabras clave: Evo-Devo, Estándares, Nuevas Hipótesis, Biología Evolutiva

\section{Abstract}

Though the evolutionary theory is part of the curricular standards given by the National Education Ministry, the advances that have happened in the last three decades about evolutionary mechanisms do not exist explicitly as a standard to be taught in the area of Biology in the schools.

${ }^{1}$ Biólogo, Universidad Nacional, Bogotá. Especialista en la Enseñanza de la Biología, Universidad Pedagógica Nacional, Bogotá. E-mail gchavesm@ecci.edu.co 
The previous thing might be due to the lack of a continuous update of the biology programs, which should be prevailing, since as explanations of new mechanisms, pace and factors of biological evolution advance, likewise these advances must be taught in the school. According to this, this essay will try to give a general vision on how the hypothesis evo-devo (evolutionary and development biology) arose and how possibly it should be understood and taught by biological sciences teachers in order to improve and update Biology teaching and learning processes in the classrooms.

\section{KEY WORDS}

Evo-Devo,standards, new hypotheses, evolutionary biology

\section{¿QUÉ ES EVO-DEVO?}

\section{Desarrollo histórico}

De una manera somera, hablar de las relaciones entre evolución y desarrollo embrionario puede dar la impresión de estar tratando temas muy disímiles de la Biología. Sin embargo, en dos períodos históricos el estudio de la evolución y el del desarrollo embrionario han transitado en paralelo. Uno fue el último tercio del siglo XIX, como se tratará luego en este ensayo y el otro lo estamos viviendo desde hace algunos años. Posiblemente este momento actual sea recordado por ulteriores historiadores de la ciencia como el del origen de un nuevo paradigma en Biología Evolutiva, una nueva síntesis que ha recibido el nombre de «Evo-Devo» (por Evolution and Development Biology).

Existe un gran consenso (no absoluto), al interior de la comunidad científica, de que la evolución biológica es un hecho y que uno de sus principales mecanismos es la selección natural, no obstante, existen algunos sectores científicos que proponen otros mecanismos de evolución biológica que no basan su poder explicativo exclusivamente en la selección natural, tales como: la deriva genética, la evolución neutralista, cambios no adaptativos, críticas al programa adaptacionista, entre otros. Sin embargo la mayoría de la comunidad científica se acerca más a la visión que propone el biólogo evolutivo Jerry Coyne en el marco de una serie de conferencias que convocó a un gran grupo de expertos en el tema:

"La teoría de la selección es un gran trabajo -el más grande en Biología-. Explica cómo cada adaptación evolucionó paso a paso. Esto incluye no sólo la forma y color del cuerpo sino también los sistemas metabólicos, el sistema nerviosos, el maravilloso sistema inmunológico etc." (Coyne, 2009 p.119)

Parafraseando a Dawkins (1988), la selección natural actúa no aleatoriamente sobre la supervivencia de variantes sucedidas aleatoriamente, favoreciendo la persistencia y la reproducción diferencial de los individuos que portan dichas variantes. Estas variaciones se presentan en individuos y poblaciones siendo determinadas en algunos casos por fenómenos como: mutaciones en uno o más genes, interacciones entre ellos 
(efectos pleiotrópico, ligamiento genético etc.), por expresión de complejos de genes y su variación y regulación (genes Hox) y otros muchos fenómenos estudiados por la Biología molecular, la Genética, la Biología del desarrollo, la Fisiología, etc.

En retrospectiva, es así como, al tratar el origen de la novedad, Darwin y Wallace coincidieron en proponer un mecanismo evolutivo que hacía énfasis en la supervivencia de la novedad, pero pasaron muy someramente la explicación de sus orígenes. Existe amplia corroboración empírica de que gran parte de la descendencia de una especie no alcanza la edad adulta o reproductiva y junto con la hipótesis de la supervivencia del más apto llevaron a la propuesta de que, en la lucha por la existencia, se seleccionarían las variedades más adaptativas, lo que implicaría un cambio morfo-fisiológico o de comportamiento a través de las generaciones. Sin embargo no existía aún conocimiento de cómo las novedades ventajosas surgían, debido en gran parte al hecho de que no se conocían los trabajos de Mendel.

Así pues, la evolución de la palabra "evolución" refleja la cambiante relación entre ambos principios de orden (evolución y desarrollo) en la historia de la biología. El vocablo "evolución" se usó originalmente para referirse al desarrollo, al despliegue ${ }^{2}$ de las características del organismo adulto preformadas en el germen vital (Gould 1977). Luego, tras la pérdida de aceptación del preformacionismo, los epigénetistas lo usaron para denotar la secuencia de formas generadas en el desarrollo embrionario (García, 2005). De ahí, los morfólogos transcendentales defensores de teorías recapitulacionistas, como Oken (1779-1851) y Tiedemann (1781-1861), comenzaron a usar el término indistintamente para denotar las transformaciones embrionarias o las transmutaciones de las especies (Richards, 1992).

La recapitulación, o paralelismo, fue de hecho, una de las teorías evolucionistas más en boga en el siglo XIX. Establecía que las diferentes fases del desarrollo orgánico eran un reflejo de las diferentes formas que adoptan las especies en la filogenia, por lo que la evolución y el desarrollo se consideraban parte de un mismo proceso, obedecían a una misma ley. John Hunter (1728-1793) y poco después Karl F. Kielmeyer (1795-1844), serían los primeros en proponer una teoría recapitucionalista de la filogenia (García, 2005).

Por otra parte los anatomistas Meckel (1724-1774) y Serres (1786-1868) en forma independiente abogaron también por la teoría de la recapitulación, que luego se conocería como ley de Meckel-Serres, utilizando la teoría de la recapitulación como apoyo a la idea de unidad del plan de organización, propuesta por Geoffroy SaintHilarie (1772-1844), comparando las formas adultas de animales inferiores y el estadio embriológico correspondiente de animales de nivel organizativo superior.

La llegada del darwinismo no supondría el final de las teorías recapitulacionistas. De hecho, Haeckel (1834-1919) se embarcó en la difícil tarea de tratar de integrar los

\footnotetext{
${ }^{2}$ Evolución, del latín evolvere, significa literalmente desplegar, desenrollar.
} 
fundamentos del darwinismo con todo el trabajo embriológico preexistente. La teoría evolutiva de Haeckel estaba basada en gran parte en la de Darwin, sostenía que el sistema de clasificación de las especies constituía en realidad un árbol genealógico, pero incluía además la "ley biogenética", que establecía que la ontogenia consistía en realidad en un rápida recapitulación de la filogenia, en la que el individuo repetía en su desarrollo los cambios de forma más importantes que sus ancestros habían sufrido durante su evolución filogenética bajo las leyes de la herencia y la adaptación. Al igual que los morfólogos transcendentales, Haeckel consideraba la evolución y el desarrollo como parte de un mismo proceso, sin embargo, mientras que los transcendentalistas consideraban que la evolución era un reflejo de las propiedades intrínsecas de la organización biológica, de la transformación entre tipos ideales, Haeckel, al contrario, consideraba que el motor causal del desarrollo estaba en la historia filogenética. Para Haeckel la filogenia es la causa de la ontogenia y no al revés. El organismo es para Haeckel, ante todo, un ser histórico (García, 2005).

A estas hipótesis ya existían objeciones como las del anatomista Karl Ernst von Baer (1792-1886), quien refuto la ley de Meckel y Sarres quien se preguntaba ¿Por qué los animales, durante su ontogenia, adquieren rasgos no funcionales que después desaparecen? Y afirmaba que el embrión no pasa por estadios pertenecientes a otras formas específicas sino que se separa de ellas, y que dicho embrión, de una forma animal, nunca se asemeja al adulto de otra forma animal sino a su embrión.

A principios del siglo XX se redescubrieron las leyes de Mendel cambiando el rumbo, no sólo de la teoría evolutiva, sino el de toda la Biología. Se corroboró la existencia de agentes precisos que determinaban la herencia de los caracteres, agentes que años después se conocerían como genes. Cincuenta años después, Watson y Crick develarían la naturaleza fisicoquímica y la localización de dichos factores con el modelo de la doble hélice, de esta manera, la hipótesis de que sí hay factores que determinan la herencia de los caracteres y que los cambios en dichos factores originarán cambios heredables en los caracteres, aportaría nuevas y contundentes evidencias a la teoría evolutiva. Este hecho se acopló perfectamente a lo que mucho antes de que se conociera la naturaleza cambiante de los genes De Vries formuló como la teoría de la mutación en 1903. Entre los años 1930 a 1940 se produjo la síntesis entre seleccionismo darwiniano y mutacionismo genético, dando lugar al paradigma neodarwinista sobre el cual se ha construido gran parte del andamiaje de la teoría evolutiva del siglo XX.

En la actualidad, la biología rechaza la versión literal de la teoría de la recapitulación y la ley biogenética que sostiene que el desarrollo embrionario de cada especie (ontogenia) repite completamente la historia evolutiva de dicha especie (filogenia). Mientras que, por ejemplo, se acepta la filogénesis del Homo sapiens como resultado de la evolución de algunos peces y luego de protoreptiles que derivaron en varias ramas (dinosaurios, reptiles modernos y mamíferos), no se acepta que se pueda distinguir estadios definidos de "pez", "protoreptil" y "mamífero" en el desarrollo embrionario humano. 
No obstante, a partir de la década de 1980, cuando el creciente conocimiento del control genético del desarrollo empezó a tener auge se volverían a acercar de nuevo la evolución y el desarrollo, llevando al nacimiento de la Evo-Devo. Los descubrimientos y las propuestas teóricas se sucedieron rápidamente. Stephen Jay Gould y Niles Eldredge habían propuesto a principios de los $70 \mathrm{~s}$ su modelo de los equilibrios interrumpidos. Según ellos, el registro fósil en general mostraba linajes muy poco variables a lo largo del tiempo, con episodios bruscos de aparición de nuevos linajes. Esto encajaba mal con la idea neodarwinista de la acumulación progresiva de pequeñas variaciones. Como si fuera poco se comenzaron a descubrir los genes implicados en las primeras etapas del desarrollo, siendo éstos de un número extraordinariamente reducido y además presentando frecuentes homologías entre genes de diferentes organismos. Uno de los casos más conspicuos es el de los genes del complejo Hox, algunos de ellos, por ejemplo, se encargan de organizar el eje anteroposterior de todos los animales bilaterales. El gen Pax-6 dirige la formación de ojos en mamíferos, insectos y cefalópodos, aunque los ojos resultantes sean completamente diferentes. Los genes que determinan el eje dorsoventral de los vertebrados y la mosca de la fruta Drosophila son los mismos, aunque estén invertidos: el ventral de la mosca corresponde al del dorso de los humanos y viceversa. De esta manera la descomunal diversidad morfológica y fisiológica de los animales está generada por un número muy reducido de sistemas de genes utilizando un recurso reiterado a dichos sistemas genéticos para la construcción del cuerpo del animal, lo cual implica que pequeñas variaciones en estos sistemas de genes pueden ser origen de substanciales novedades morfológicas, fisiológicas o de comportamiento innato.

Es importante señalar que la hipótesis Evo-Devo no refuta en modo alguno el neodarwinismo, sino que lo complementa en el marco de una teoría evolutiva mucho más solida y unificada. En palabras del biofilósofo Michael Ruse con respecto al EvoDevo:

"La emergencia de este nuevo campo de investigación promete una nueva síntesis para la explicación de la evolución, que no contradice al neodarwinismo sino que lo completa. La hipótesis Evo-Devo sería el campo de investigación que me gustaría elegir como materia de mi Tesis doctoral, si tuviera que hacerla ahora en el año 2005, en la cual trabajé cuarenta años antes en1965. Yo soy un darwinista de línea dura - lo que no significa ser un darwinista ortodoxo-. Pero los puros darwinistas conocen que las nuevas ideas (tales como el EvoDevo) son desafíos y oportunidades, no barreras o impedimentos" (Ruse, 2005).

En este orden de ideas, los estudios comparativos de los mecanismos del desarrollo (incluyendo los mecanismos genéticos), que pueden ser llevados a cabo a través de los taxones, hacen posible la reconstrucción detallada de los procesos de desarrollo y abren una esperanza para que los modelos teóricos del desarrollo puedan ser integrados en los modelos de la evolución basados en mecanismos neodarwinistas. 
Entre los resultados más sorprendentes y, probablemente, más contraintuitivos de la investigación en Biología evolutiva del desarrollo se encuentra el hecho de que la diversidad de los planes corporales y de la morfología de los organismos a lo largo de muchos fila no aparecen necesariamente reflejados en una diversidad a nivel de las secuencias de genes implicadas en la regulación del desarrollo. De hecho, como señalan Gerhart y Kirschner (1997), nos encontramos con una aparente paradoja: allí donde esperamos encontrar variación, encontramos conservación, ausencia de cambio, así pues incluso dentro de una misma especie, la aparición de nuevas formas dentro de una población no indica la preexistencia de variación genética suficiente para dar cuenta de la diversidad morfológica. Por ejemplo, aun cuando la variación genética es baja, se encuentra una variación amplia en la morfología de las extremidades de las salamandras por nombrar uno de muchísimos ejemplos. Con esta evidencia surgiría la pregunta: ¿De dónde emerge la novedad si la novedad morfológica que observamos a nivel de los diferentes clados no se refleja continuamente en el genoma?, la posible respuesta a esta pregunta nos lleva al siguiente apartado.

\section{Implicaciones del Evo-Devo}

La novedad puede surgir a través de varios medios, incluyendo la duplicación genética y los cambios en la regulación genética. La duplicación genética permite la fijación de una función celular o bioquímica particular en un locus, de modo que el locus duplicado queda libre para desempeñar una nueva función. Los cambios en la regulación genética son efectos de segundo orden que resultan de la interacción y del ritmo de actividad de las redes genéticas, propiedades distintas del funcionamiento de los genes individuales en la red.

El descubrimiento en la década de los ochenta de los genes Hox ${ }^{3}$ permitió que los investigadores en biología del desarrollo evaluaran empíricamente la importancia relativa de la duplicación y de la regulación genética en la evolución de la diversidad morfológica. Varios biólogos sugieren que los cambios en los sistemas regulatorios de los genes son más significativos que los cambios en el número de genes o en la función de las proteínas (Carroll 2000). De esta manera el Evo-Devo es una de las áreas más innovadoras en genética, y combina la embriología comparada, la filogenia molecular, el análisis genómico y la paleontología.

\footnotetext{
${ }^{3}$ Los genes Hox regulan múltiples aspectos del desarrollo embriológico en seres vivos como el hombre y la mosca. Son sistemas genéticos de control del desarrollo biológico muy conservados en la evolución, se consideran una auténtica piedra Rosetta en este campo de la investigación. Los genes Hox forman una familia génica que codifica para factores de transcripción del desarrollo. Se agrupan en un clúster o conjunto de genes que es el resultado de la duplicación en tándem de un gen primordial. Se ordenan de manera lineal y consecutiva en el genoma, en un patrón genético que refleja a su vez el orden de expresión temporal y espacial, y son genes que determinan la posición de diferentes órganos y estructuras (cabeza, cola, extremidades, etc.) en animales con simetría bilateral. Muchas de las diferencias que observamos en la morfología de los metazoos son el resultado de cambios en el número, regulación y zonas de expresión de los genes Hox, así pues estudiar su historia evolutiva, es un punto clave para entender y reconstruir la evolución de los planes corporales bilaterales en el árbol filogenético de los metazoos.
} 
El Evo-Devo sostiene que la naturaleza combinatoria de la regulación de la transcripción genética proporciona un rico sustrato para la diversidad morfológica, dado que las variaciones en el nivel, patrón o ritmo de la expresión genética pueden proporcionar más variación para que la selección natural actúe sobre ellos, que los cambios que se producen solamente en el producto génico. Los cambios epigenéticos ${ }^{4}$ incluyen la modificación del material genético debida a alteraciones químicas reversibles (Jablonka y Lamb, 1995) así como la remodelación no programada del organismo por efectos ambientales, debida a la inherente plasticidad fenotípica de los organismos en desarrollo (West-Eberhard, 2003). Los biólogos Stuart A. Newman y Gerd B. Müller han sugerido que los primeros organismos en la historia de la vida multicelular eran más susceptibles a esta segunda categoría de la determinación epigenética que los organismos modernos. Teniendo en cuenta lo anterior, comprender la hipótesis evo-devo podría dar luces para responder preguntas de suma importancia biológica y filosófica como ¿qué es la vida?, ¿cómo inició la vida? y ¿cómo evolucionó y evoluciona la vida?

\section{CONSIDERACIONES DIDÁCTICAS}

\section{La hipótesis Evo-Devo en libros de texto de educación secundaria básica y media vocacional.}

Al consultar los siguientes libros de texto enumerados a continuación, los cuales son de frecuente uso en las instituciones educativas privadas como públicas, no se encuentra ni la más mínima mención a la hipótesis Evo-Devo.

1. TÍTULO: Biología AUTORES: Alton Biggs y Whotney Crispen, GRADO DE SECUNDARIA AL QUE ESTA DIRIGIDO: Sexto, EDITORIAL: McGraw Hill Interamericana S.A. (2009).

2. TÍTULO: Biología la Dinámica de la vida, AUTORES: Biggs, Kapicka, Lundgren, GRADO DE SECUNDARIA AL QUE ESTA DIRIGIDO: Decimo y Once, EDITORIAL: McGraw Hill Interamericana S.A.(2009)

3. TÍTULO: Biología la Unidad y la Diversidad de la Vida, AUTORES: Cecie Starr Ralph Taggart, GRADO DE SECUNDARIA AL QUE ESTA DIRIGIDO: Sexto, Séptimo y Octavo, EDITORIAL: Cengage Learning (2009).

\footnotetext{
${ }^{4}$ Epigenética se refiere al estudio de todos aquellos factores no genéticos que intervienen en la determinación del desarrollo de un organismo y dependiendo de la disciplina biológica, el término epigenética tiene diversos significados: En genética del desarrollo, hace referencia a los mecanismos de regulación genética que no implican cambios en la secuencias de ADN; en biología del desarrollo, hace referencia a la dependencia de los procesos embriológicos; en biología evolutiva, el término herencia epigenética engloba a los mecanismos de herencia no genéticos.
} 
4. TÍTULO: Inteligencia Científica, AUTORES: Salamanca, G., GRADO DE SECUNDARIA AL QUE ESTA DIRIGIDO: noveno, EDITORIAL: Voluntad.(2003)

\author{
5. TÍTULO: Ciencias 9, AUTORES: Torres F., GRADO DE SECUNDARIA AL QUE \\ ESTA DIRIGIDO: Noveno, EDITORIAL: Prentice Hall. (2003).
}

Es importante hacer notar que en libros como Biología, (Curtis et al., 2007), el cual está dirigido a estudiantes universitarios, sí se encuentran menciones explicitas y amplias sobre el Evo-Devo que tratan sobre el origen de la hipótesis, cómo ésta se relaciona con disciplinas como la genética y la embriología y cómo ésta hipótesis complementa las explicaciones neodarwinistas del fenómeno evolutivo.

\title{
La hipótesis Evo-Devo en Estándares Básicos de Competencias en Ciencias Naturales para Colombia
}

En la cartilla de Estándares Básicos de Competencias en Ciencias Naturales propuestos por el Ministerio de educación Nacional (MEN) en el año 2004 y en vigencia encontramos los siguientes loables propósitos en lo que se refiere a la enseñanza de las Ciencias, como el siguiente:

"La propuesta que aquí presentamos al país busca crear condiciones para que nuestros estudiantes sepan qué son las ciencias naturales, y también para que puedan comprenderlas, comunicar y compartir sus experiencias y sus hallazgos, actuar con ellas en la vida real y hacer aportes a la construcción y al mejoramiento de su entorno, tal como lo hacen los científicos.

Buscamos que estudiantes, maestros y maestras se acerquen al estudio de las ciencias como científicos y como investigadores, pues todo científico se aproxima al conocimiento de una manera similar, partiendo de preguntas, conjeturas o hipótesis que inicialmente surgen de su curiosidad ante la observación del entorno y de su capacidad para analizar lo que observa" (Formar en Ciencias: el desafío, MEN, 2004 p.6 y p. 8). 
Pero para ser congruentes con lo propuesto en las frases "tal y como lo hacen los científicos o acercarse a la ciencia como científico", se debe tener en cuenta que todo aquel que actúe como científico, debe de estar en constante proceso de actualización, con el fin de comprender nuevas hipótesis y planteamientos tales como las que propone el Evo-Devo, en pos de mejorar el entendimiento científico de antiguos pero vigentes interrogantes, como los que se plantearon en los primeros apartados de este ensayo.

En cuanto a lo que es específicamente la enseñanza de la evolución biológica encontramos en los Estándares Básicos en Ciencias las siguientes competencias que se esperaría que deban alcanzar los estudiantes:

\begin{abstract}
"Explico el origen del universo y de la vida a partir de varias teorías. Formulo hipótesis acerca del origen y evolución de un grupo de organismos. Establezco relaciones entre el clima en las diferentes eras geológicas y las adaptaciones de los seres vivos Comparo diferentes teorías sobre el origen de las especies" (Formar en Ciencias: el desafío, MEN, 2004 p.20).
\end{abstract}

Como se puede observar no existe explícitamente una competencia que se refiera a las nuevas hipótesis en evolución biológica, como tampoco una mención al Evo-Devo.

\title{
¿Cómo se podría asumir el reto de la enseñanza de la hipótesis Evo-Devo?
}

En este apartado se darán algunas sugerencias de cómo podrían los maestros de biología asumir desde el ejercicio docente, y también desde las reflexiones didácticas y epistemológicas, la enseñanza de nuevas hipótesis en evolución biológica tales como el Evo-Devo.

1. El maestro de biología debe ser consciente de que las diferentes teorías que explican los fenómenos biológicos, como la evolución biológica, están en constante cambio y actualización. A pesar de que teorías como la evolución por selección natural han resistido el paso del tiempo, dichas teorías deben y necesitan ser complementadas con nuevas hipótesis, hechos y corroboraciones científicas.

2. Los maestros de Biología deben tener en cuenta que si bien es de suma importancia que los estudiantes comprendan la teoría de evolución por selección natural, hay que tener en consideración otros mecanismos no darwinianos que explican y complementan los fenómenos evolutivos,

3. Se debe mostrar a los estudiantes el desarrollo histórico de las diferentes teorías que explican la evolución biológica con una mirada que incluya una visión epistemológica de los hechos históricos que han hecho posibles las diferentes hipótesis y teorías que explican los fenómenos evolutivos. 
4. Es de suma importancia el entendimiento de la genética clásica como también de la citogenética y de la genética molecular, sin embargo no se debe vender a los estudiantes la falsa promesa de que todo en biología está determinado y puede ser explicado solamente en virtud de los genes, el ADN, etc. En Ciencia y en particular en Biología es importante tener una visión holística de los fenómenos naturales. En este orden de ideas, las explicaciones sobre fenómenos evolutivos y de desarrollo deben tener en cuenta lo genotípico y lo ambiental

5. Sería muy importante que los maestros de biología de secundaria tomen el riesgo de complementar el uso de los libros de texto propios de cada curso, con el uso de textos de nivel universitario, los cuales en muchos casos están mucho mas actualizados en cuanto a nuevas hipótesis biológicas. También sería deseable alentar a los estudiantes a la lectura de libros de divulgación científica que tratan sobre nuevas hipótesis biológicas tales como:

- Ontogenia y Filogenia ( Gould, 1977)

- Deconstruyendo a Darwin (Sampedro, 2002)

- El relojero ciego (Dawkins, 1988)

- Charles Darwin (Ruse, 2005)

Es importante aclarar que para el uso de estos libros, (textos universitarios y obras de divulgación científica) como complemento a los diferentes procesos de enseñanza-aprendizaje, se debe lograr una adecuada transposición didáctica ${ }^{5}$ de los contenidos de éstos, teniendo en cuenta el nivel educativo de los estudiantes, lo anterior en virtud de la dificultad de comprensión que pueden presentar estas lecturas dada la complejidad de algunos de éstos libros.

6. Se debe tener en cuenta la relevancia de la enseñanza de la embriología, teniendo en cuenta que ésta es la disciplina que estudia sobre el origen, crecimiento, desarrollo y función de un organismo, desde la fertilización hasta el nacimiento. Además la embriología comparada, permite observar embriones de diversos organismos, como por ejemplo el de los vertebrados, en los cuales se puede ver el evidente parecido ${ }^{6}$. Si la comparación la hacemos con embriones de la misma clase dentro de los vertebrados, el parecido será aún mayor, con lo cual las relaciones filogenéticas pueden hacerse claras y particularmente evidentes.

\footnotetext{
${ }^{5}$ La transposición didáctica es el proceso por el cual ciertos contenidos seleccionados a enseñar en un tiempo y lugar dados, son transformados en contenidos enseñables. Es decir, es la transformación del saber científico en un saber posible de ser enseñado. Para nuestro caso, dichos saberes científicos serian los temas actuales, controversias, nuevos descubrimientos, nuevas hipótesis que a discreción del maestro puedan mejorar los procesos de enseñanza de la Biología.

${ }^{6}$ Se hacen evidentes los parecidos, no la recapitulación de estadios definidos (pez, reptil mamífero etc.)
} 
7. Es importante destacar que el trabajo en laboratorio, enfocado hacia la embriología comparada, no es muy complicado de llevar a cabo en las aulas de clase, esto, en virtud de que los micropreparados permanentes que muestran diferentes estadios del desarrollo embriológico de diferentes especies como la mosca de la fruta, pollos, cerdos, humanos son económicos y fáciles de conseguir y con ellos se puede mostrar a los estudiantes evidencia observable y tangible de las relaciones filogenéticas existentes entre diferentes grupos de organismos.

\section{BIBLIOGRAFÍA}

Alton, B. y Whotney, C. (2009). Biología. México D.F.: McGraw Hill Interamericana S.A. $605 p$.

Carroll, S. (2000). Endless forms: the evolution of gene regulation and morphological diversity. Cambridge : Harvard Univ. Press. $580 \mathrm{p}$

Cecie S. y Ralph T. (2009). Biología la Unidad y la Diversidad de la Vida. Michigan: Cengage Learning. $423 \mathrm{p}$.

Coyne, J. (2009). Why evolution is true. New York: Viking 357p.

Curtis, H., Barnes, N., Schnek, A., Massarini, A. (2009). Biología. Séptima edición.

Buenos Aires: Panamericana. 1026 p.

Dawkins, R. (1988). El relojero ciego. Barcelona: Labor. 322p.

Garcia, T (2005). Evolución, desarrollo y (auto)organización. Un estudio

sobre los principios filosóficos del Evo-Devo. (Disertación Doctoral, Universidad del País Vasco. España, 2005)

Gerhart, J. Kirschner, M. (1997) Cells, Embryos, and Evolution: Towards a Cellular and Developmental Understanding of Phenotypic Variation and Evolutionary Adaptability. Cambridge: Wiley. 656 p.

Gould, S. (1977). Ontogeny and Phylogeny. Cambridge MA: Harvard University Press. $467 \mathrm{p}$.

Kapicka, L., Biggs, S., Lundgren, H. (2009). Biología la Dinámica de la vida. México D.F.: McGraw Hill Interamericana S.A.(2009). 415 p.

Ministerio de Educación Nacional. (2004). Formar en Ciencias: El Desafío. Bogotá: Ed. MEN. 
Muñoz, R. (2009). Evo-Devo: Hacia un nuevo paradigma en Biología Evolutiva. Universidad de Málaga. Visto el 9 de diciembre de 2009 en: http://www.encuentros.uma.es/encuentros100/evodevo.htm

Ruse, M. (2005). Charles Darwin. Buenos Aires: Katz. 243 p.

Salamanca, G. (2003). Inteligencia Científica. Bogotá: Voluntad. 256 p.

Sanpedro, J. (2002). Deconstruyendo a Darwin. Barcelona: Crítica. 290 p.

Torres, F. (2003). Ciencias 9. México: Prentice Hall. 324 p.

West-Eberhard, M. (2003). Developmental Plasticity and Evolution, Oxford: University Press. 401 p. 